\title{
Neu im Bundesvorstand
}

Geboren und aufgewachsen im Rheinland, zwischen Düsseldorf und Köln. Nach dem Abitur an einem neusprachlichen Gymnasium für Mädchen Aufnahme des Studiums der Rechtswissenschaften, zunächst an der Justus-LiebigUniversität Gießen. Motiv für die Wahl des Studienfaches ist ein ausgeprägtes Interesse an der Sprache als Instrument und der Auslegung von Texten. Nach zwei Semestern Wechsel an die Universität Köln. Studentische Hilfskraft am dortigen Institut für Versicherungsrecht. Referendariat in Köln. Nach dem 2. Staatsexamen zunächst als Rechtsanwältin am Landgericht Köln zugelassen; Tätigkeit in zwei Kanzleien mit vorwiegend bzw. ausschließlich versicherungsrechtlichen Mandaten.

Danach in den richterlichen Dienst des Landes Nordrhein-Westfalen eingetreten und im Bereich des Oberlandesgerichts Düsseldorf als Richterin zunächst bei dem Landgericht Mönchengladbach in Zivil- und Strafsachen tätig. Ernennung zur Richterin am Amtsgericht, Zivilsachen, Bußgeldsachen und Vorsitzende eines Jugendschöffengerichts.
Mitte der 90er Jahre Abordnung an das Amtsgericht Potsdam, tätig als Zivilrichterin und wiederum Vorsitzende eines Jugendschöffengerichts. Zusätzlich Übernahme der Aufgabe der Pressesprecherin des Amtsgerichts Potsdam.

Nach Abordnung an das Brandenburgische Oberlandesgericht Versetzung in den richterlichen Dienst des Landes Brandenburg und Ernennung zur Richterin am Oberlandesgericht. Insgesamt fünf Jahre in einem Zivilsenat tätig, der zu 40 Prozent Bausachen bearbeitete. Seit 1. Januar 2001 im 2. Strafsenat, zuständig für Rechtsbeschwerden, Revisionen, allgemeine Beschwerden in Strafsachen, Rehabilitierungsverfahren u.a., inzwischen als Vorsitzende Richterin am Oberlandesgericht.

Neben der richterlichen Tätigkeit für mehr als neun Jahre Pressesprecherin des Brandenburgischen Oberlandesgerichts. Seit 2002 Gleichstellungsbeauftragte des Brandenburgischen Oberlandesgerichts und mit Inkrafttreten dieses Gesetzes Beschwerdestelle nach dem AGG.

Seit Dezember 2006 Vorsitzende des Landesverbandes Brandenburg.
Mein Name ist Anna Eberhard, ich bin Referendarin am Landgericht Bonn.

Ich wurde am 31. Juli 1980 in Bonn geboren und bin im Rheinland aufgewachsen. Im Sommer 2000 habe ich mein Studium in Münster begonnen. Während des Studiums zog es mich für ein Semester nach Padua. Nach dem Examen Anfang 2005 habe ich mich für einen Masterstudiengang im Europäischen und internationalen Recht in Bremen entschieden, der mich für ein dreimonatiges Praktikum ins Kosovo führte. Im Oktober 2006 bin ich mit meinem Mann ins Rheinland zurückgekehrt und seitdem Referendarin am LG Bonn.
Ich wurde bereits zu Beginn meines Studiums in Münster djb-Mitglied. In Bonn übernahm ich das Amt der „Jungen Juristin vor Ort", engagiere mich für die Neugewinnung jüngerer Mitglieder und setzte mich für ihre Interessen ein.

Diese Erfahrungen möchte ich nun auch in meine Arbeit im Bundesvorstand als Vertreterin der Juristinnen in Ausbildung einbringen und nutzen. Dabei möchte ich besonders die Vernetzung der „Jungen Juristinnen“ untereinander sowie zwischen älteren und jüngeren Mitgliedern weiter unterstützen.

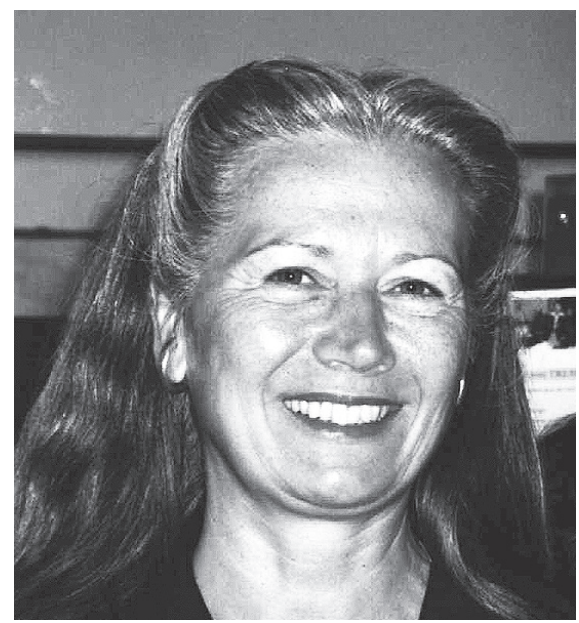

Ramona Pisal

Vizepräsidentin

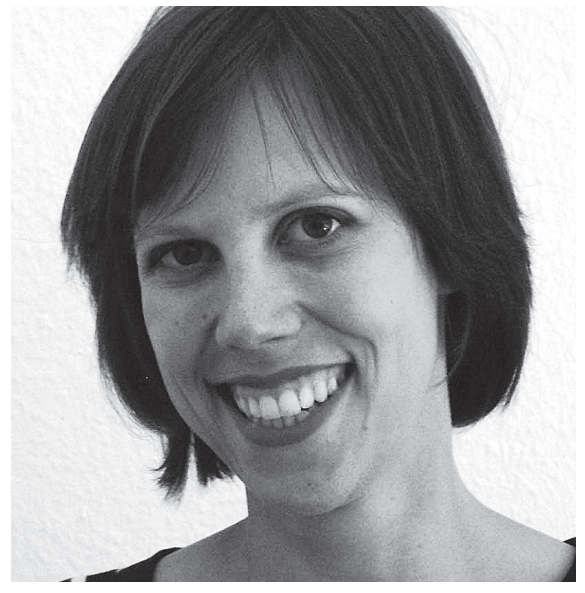

Anna Eberhard

Vertreterin der Juristinnen in Ausbildung 